\title{
Protective Effects of Nitric Oxide and Phycocyanin Against Oxidative Stress Induced by Hepatic Ischemia/Reperfusion Injuries
}

\author{
Neyla Ben Gdara*, Ikram Khemiri, Amel Belgacem, Safa Mannai, Lotfi Bitri
}

Department of Biology, University of Tunis El Manar, Faculty of Sciences of Tunis, University campus 2092, El Manar, Tunis, Tunisia

\section{Article Info}

\section{Article Notes}

Received: July 05, 2018

Accepted: July 31, 2018

\section{*Correspondence:}

Dr. Neyla Ben Gdara, Department of Biology, University of Tunis El Manar, Faculty of Sciences of Tunis, University campus 2092, El Manar, Tunis, Tunisia; Telephone No: 0021620610099;

Email: neylabengdara@yahoo.fr.

C 2018 Gdara NB. This article is distributed under the terms of the Creative Commons Attribution 4.0 International License.

\section{Keywords:}

schemia-reperfusion

Oxidative stress

Phycocyanin

Nitric oxide

Preservation solution

Cold ischemia
Abstract

Liver ischemia-reperfusion induced hepatocellular damage that contributes to the morbidity and mortality ${ }^{1,2}$ associated with shock, thermal injury, re-sectional surgery and liver transplantation. One of the earliest events associated with reperfusion of ischemic liver is the release of Reactive Oxygen Species (ROS) causing oxidative stress. The following review focuses on the antioxidant effects of nitric oxide (NO) and Phycocyanin (Pc) after cold ischemia/reperfusion injury (IRI). In this regard, this review investigates in the first part the effect of the addition of $\mathrm{NO}$ to the preservation solution at different concentrations $(1000,500$ and $50 \mathrm{nM})$ and in the second part the effect of the addition of phycocyanin to the conservation solution at two doses $(0.2 \mathrm{mg} / \mathrm{ml} / \mathrm{g}$ of liver and $0.1 \mathrm{mg} / \mathrm{ml} / \mathrm{g}$ of liver) on liver graft quality. In conclusion, phycocyanin and nitric oxide (at a low dose) are effective in preserving the hepatic graft and protecting it against IRI by acting as a potent antioxidant against the products of oxidative stress.

\section{Introduction}

Organ transplantation was described in the early 20th century, in the development of the first successful vascular anastomosis by Carell $^{3}$. But it was only in 1954 that the human kidney was successfully transplanted by Murray ${ }^{4}$. Since organ transplantation has been a success and a significant evolution through advances in the field of removal techniques and implants preservation which has allowed an increase in life expectancy and has a marked improvement in the quality of patient's life after transplantation ${ }^{5}$. Different metabolic changes take place during different steps of the liver transplantation procedure. After liver preservation and before transplantation, the hepatic graft undergoes diverse and complex molecular, cellular and biochemical alterations known as ischemia/reperfusion syndrome (IR) ${ }^{6,7}$. During transplantation, the hepatic graft is subject to two constraints: ischemia or lack of blood circulation and reperfusion. There are two types of ischemia, cold ischemia and warm ischemia followed by reperfusion ${ }^{8}$. During cold ischemia, the hepatic graft undergoes a serious damage associated with a reduction of cellular ATP levels, and an enhancement of cytosolic calcium levels ${ }^{9}$, leading to primary liver graft dysfunction. The restoration of blood flow during reperfusion has paradoxical consequences for the ischemic tissue. First, it will initiate a number of events responsible for the extension of tissue lesions. It is the paradox of oxygen ${ }^{10}$. The reperfusion phase is also characterized 
by production and release of Reactive Oxygen Species (ROS) which are the main mediators of hepatic ischemiareperfusion injury (IRI) ${ }^{11,12}$, and later by an inflammatory disorder mediated by the activation of Kupffer cells, endothelial and parenchymatous cells damage ${ }^{13}$.The graft cold preservation is one of the main principles of organ persistence that prolongs the preservation time and improves the quality of the graft. This review summarized recent findings about the improvement of the composition of the preservation solution by the addition of pharmacologically active substances to reduce IR lesions. The isolated perfused rat liver was used. The first part of this review focuses on the addition of sodium nitrite $\left(\mathrm{NaNO}_{2}\right)$ to the conservation solution Institut Georges Lopez-1 (IGL-1) at different concentrations (1000, 500, and $50 \mathrm{nM}$ ). The second part focuses on the effect of added phycocyanin, the main pigment of Spirulina (Spirulina platensis) to the Krebs Henseleit preservation solution $(\mathrm{KH})$ at two different doses $(0.1 \mathrm{mg} / \mathrm{ml} / \mathrm{g}$ of liver, $0.2 \mathrm{mg} /$ $\mathrm{ml} / \mathrm{g}$ of liver) on the functional parameters of the liver.

\section{Conservation Solutions}

The use of a preservation solution is an important part of organ preservation. Several preservation solutions have been developed to extend the viability of the graft. Thus in this work, two preservation solutions were used for liver graft preservation: IGL-1 solution and KH solution.

\section{Hypothermic Conservation}

After hepatectomy, and in the first part of the present study, livers were immersed in a cylindrical plastic vial containing $40 \mathrm{ml}$ of IGL and IGL+ NO solutions at $4^{\circ} \mathrm{C}$ and $40 \mathrm{ml}$ of Krebs Henseleit bicarbonate buffer supplemented with mannitol and glutathione (reduced form), $\mathrm{pH}=7.30$ at $4{ }^{\circ} \mathrm{C}(\mathrm{KH}$ and $\mathrm{KH}+$ phycocyanin) for the second part of this study. Then, the plastic vial is placed in the refrigerator for 24 hours.

\section{Liver Perfusion Experiments}

Livers were perfused with an isotonic Krebs Henseleit (KH) solution saturated with $95 \% \mathrm{O}_{2} / 5 \% \mathrm{CO}_{2}$, according to the technique described previously ${ }^{14,15,16}$. Perfusions were performed in a closed circuit, in a humid thermoregulated chamber $\left(37^{\circ} \mathrm{C}\right)$ during 120 minutes. The perfusion fluid circulation was provided by a peristaltic pump at constant pressure and calibrated for a basal hepatic flow rate about $3 \mathrm{ml} / \mathrm{min} / \mathrm{g}$ liver ${ }^{17,18}$. Before starting the experimental protocol, livers were perfused in single-pass mode for 15 min to ensure the rinsing of liver and their stabilization. Once the peristaltic pump is running, the perfusion fluid returns to the livers through the portal vein and exits through the lower vena cava before returning to the pump. Livers have been perfused in a recirculation mode. Samples of liver effluents were collected every $10 \mathrm{~min}$ to determine liver toxicity parameters and tissue samples were taken from the left lateral hepatic lobe at the end of reperfusion and subsequently frozen at $-20^{\circ} \mathrm{C}$ until malondialdéhyde (MDA) and antioxidant enzymes assay.

\section{Discussion}

\section{Effect of hypothermic conservation}

Hypothermia is the essential element of the preservation. Hypothermic conservation has controversial effects upon the transplantation graft; it prolongs the preservation period and at the same time causes adverse effects to the cell by inhibiting metabolic enzyme activities ${ }^{19}$. In fact, cold ischemia is associated with lower cellular ATP levels, reduced oxidative phosphorylation, alteration of the calcium homeostasis and cellular edema ${ }^{19}$, while reperfusion leads to greater mitochondrial dysfunction and production of ROS responsible for oxidative stress ${ }^{20}$. All these events lead to the alteration of the microvascular system and lesions of the hepatic parenchyma. The effect of cold ischemia on the quality of hepatic graft, using the perfused isolated rat liver model, demonstrated an increase in hepatocellular lesions during reperfusion after 24 hours of cold ischemia. Livers stored for a period of $24 \mathrm{~h}$ in the conservation solutions, release more transaminases; aspartate aminotransferase (AST) and alanine aminotransferase (ALT) in the perfusion liquid after the end of the reperfusion (at $t=120$ minutes). The presence of these enzymes in the perfusion fluid is a reflection of hepatocellular lysis caused by cold ischemia and reperfusion. During ischemia/reperfusion, several ROS are involved ${ }^{21}$, inducing a state of oxidative stress. In fact, the liver tissue of rats challenged with cold ischemia followed by reperfusion underwent a significant increase in lipid peroxidation (MDA). During reperfusion, the mitochondrial ROS generation increases notably ${ }^{22,23}$ causing an alteration of the mitochondrial respiratory chain and an appearance of severe hepatocellular lesions ${ }^{24,25}$. Glutamate dehydrogenase (GLDH), a liver cell mitochondrial enzyme, is used as an indirect marker of mitochondrial lesions. We have noted a significant activity increase after $24 \mathrm{~h}$ hypothermic storage. In conclusion, During cold ischemia, the electron transport chain of the mitochondria is disturbed, resulting in leakage of electrons and uncoupling of the respiratory chain during reperfusion, leading to high ROS production ${ }^{26,27}$. A significant increase in lipid peroxidation was accompanied by a real decrease in the protein thiol levels and a marked enhancement in the activities of the antioxidant enzymes glutathione peroxidase (GPx) and glutathione S-transferase (GST), after 24h of cold ischemia. These principal enzymes constitute the second line of enzymatic defense, which play an important role in the detoxification of the endogenous and the exogenous toxic compounds ${ }^{28}$. An acute inflammatory response, characterized by Kupffer cells activation takes place during reperfusion period ${ }^{29,30}$. Once activated, these cells generate ROS and release other inflammatory mediators, such as 
cytokines and chemokines responsible of hepatocellular and endothelial lesions in the late period of reperfusion ${ }^{31}$.

\section{Effect of nitric oxide on hypothermic conservation}

NO has a significant role in the prevention of I/R injury. Indeed, thebioavailability ofNO is reduced at thebeginning of hepatic graft reperfusion ${ }^{32}$. This decrease is associated with tissue damage and endothelial dysfunction that occurred during I/ $\mathrm{R}^{33}$. Two NO synthesis pathways were developed: the endogenous pathway and the exogenous pathway. NO can be produced in the endogenous pathway, from a NO precursor, L-arginine, by endothelial nitric oxide synthase (e-NOS). L-arginine has shown to have protective potential during transplantation ${ }^{34}$. It promotes NO production by hepatocytes in order to limit hepatocellular lesions. The exogenous pathway requires the exogenous source of NO, either by direct inhalation or by NO donors such as sodium nitroprusside (SNP) ${ }^{35}$ or S-nitroso-L-glutathione (GNSO) ${ }^{36}$ The beneficial effects of SNP have been demonstrated by Kuroki and associates ${ }^{37}$, who administrated nitroprusside to the rat kidney during reperfusion and found an increase of hepatic microcirculation and reduced hepatocyte damage. Another exogenous source of NO would be nitrite anion $\left(\mathrm{NO}_{2}^{-}\right)$produced under hypoxia and acidosis conditions. In fact, $\mathrm{NO}_{2}^{-}$can be reduced to $\mathrm{NO}$ by the action of xanthine oxidoreductase $(\mathrm{XOR})^{38}$, deoxygenated hemoglobin ${ }^{39}$ and the decrease in $\mathrm{pH}^{40}$. Several studies have evaluated the effect of nitrite on functional recovery of liver after warm ischemia ${ }^{41}$. Results showed that nitrite-dependent NO production significantly decreased I/R lesions in liver and heart. The beneficial effects of NO have been demonstrated in a recent study, in which ischemic livers were preserved at $4^{\circ} \mathrm{C}$ for 24 hours in the IGL-1 solution enriched with different concentrations of $\mathrm{NaNO}_{2}(1000,500$ and $50 \mathrm{nM})$. We concluded in this study that a low concentration of nitrite $(50 \mathrm{nM})$ seems to be protective against I/R lesions, whereas a high concentration of nitrite $(500,1000 \mathrm{nM})$ can generate adverse effects. Indeed, a high concentration of $\mathrm{NaNO}_{2}$ induces the production of a large amount of NO, which can react with $\mathrm{O}_{2}^{-}$to form the $\mathrm{ONOO}^{-}$, a very toxic compound for the cell ${ }^{42}$. Therefore, the addition of nitrite to the storage solution (IGL-1) at a low dose (50 nM) decreased oxidative stress (decrease in MDA concentration) and provided protection against mitochondrial damage (decrease in GLDH concentration), thereby maintaining the integrity of liver cells and protecting the graft against cytolysis (decreased transaminases) ${ }^{43}$.

\section{Effect of phycocyanin on hypothermic conservation}

Phycocyanin (Pc) is the principal pigment of Spirulina, a microalgae which have been widely used in many countries as a dietary supplement ${ }^{44}$. Previously, several studies have demonstrated the hepatoprotective ${ }^{45}$, antiinflammatory ${ }^{45,46}$ and antioxidant ${ }^{47,48}$ properties of Pc. The presence of Pc in the preservation solution can reduce I/R damages and optimize the quality of the preserved graft. Its therapeutic power consists in eliminating the excessive formation of ROS. Its huge scavenger activity is mediated by its major component, phycocyanobilin (PCB) which is a chromophore-tetrapyrrole chain, similar to bilirubin $^{31,49}$. The latter plays an antioxidant role for the reactive species ${ }^{50,51}$. Previous reports have shown that in experimental models in vivo and in vitro, Pc protects cells from lipid peroxidation damage induced by oxidative stress through scavenging $\mathrm{ROS}^{29,52}$. Recently, our research team demonstrated the beneficial effects of phycocyanin on the ischemically damaged rat liver. We have concluded that treatment with phycocyanin at the concentration of $0.2 \mathrm{mg} / \mathrm{ml} / \mathrm{g}$ of liver normalizes levels of transaminases (AST and ALT), lipid peroxidation (MDA), and thiol groups as well as the activity of the antioxidant enzymes studied, whereas phycocyanin pretreatment at the concentration of $0.1 \mathrm{mg} / \mathrm{ml} / \mathrm{g}$ of liver seems to reduce only GST and alkaline phosphatase (ALP) levels after 24 hours of hypothermic storage ${ }^{53}$.

\section{Conclusion}

Taking into account these findings, it's clear that the improvement of the composition of the preservation solution is necessary in order to optimize the quality of the preserved graft and to limit ischemia/reperfusion injury. The additions of a dose of $50 \mathrm{nM}$ of nitrite or $0.2 \mathrm{mg} / \mathrm{ml} / \mathrm{g}$ of liver of phycocyanin to cold preservation solutions may protect livers from cold I/R injury through their strong antioxidant potentials.

\section{Acknowledgements}

Author acknowledgement: Ikram Khemiri_for the writing assistance.

\section{References}

1. Işık A, Sayar İ, Gülhan B, et al. Fascioliasis: A Rare Case Mimicking Cholelithiasis. J Kartal TR. 2016; 27(2): 145-146.

2. Işık A, Fırat D, Soytürk M, et al. Safra Kesesi Duplikasyonu. Gazi Medical Journal. 2016; 27(3).

3. Carell A. Results of the transplantation of blood vessels, organ and limbs. Jamas. 1908; 51: 1662.

4. Murray JE, Tilney NL, Wilson RE. Renal transplantation: a twenty-five year experience. Ann Surg. 1976; 184: 565.

5. Fuller BJ. Organ preservation: the profit and loss account of using hypothermia to maintain viability. Transplant Rev. 1999; 13: 55-66.

6. Brass CA, Nunes F, Negpal R. Increased oxyradical production during reoxygenation of perfused rat liver. Transplant. 1994; 58(12): 13291335.

7. Jamieson NV. Improved preservation of liver for transplantation. Aliment Pharmacolther. 1991; 5(2): 91-104.

8. Selzner N, Rudiger $\mathrm{H}$, Graf $\mathrm{R}$, et al. Protective strategies against ischemic injury of the liver. Gastroenterol. 2003; 125(3): 917-936.

9. Auger S, Vallerand D, Hadded PS. Cold preservation-warm reperfusion 
perturbs cytosolic calcium homeostasis in rat liver sinusoidal endothelium cells. Liver Transpl. 2003; 9(2): 150-159.

10. Eschwège $P$. What information is provided by transplantation on renal protection. Ann Fr Anesth Reanim. 2005; 24(2): 182-193.

11. Zhou G, Dada LA, Wu M, et al. Hypoxia-induced alveolar epithelialmesenchymal transition requires mitochondrial ROS and hypoxiainducible factor 1. Am J P Lung. 2009; 297(6): 1120-1130.

12. Glantzounis GK, Salacinski HJ, Yang w, et al. The contemporary role of antioxydant therapy in attenuating liver ischemia-reperfusion injury: A review. Liver Transpl. 2005; 11(9): 1031-1047.

13. Jaeschke H, Farhood A. Neutrophil and Kupffer cell-induced oxidant stress and ischemia-reperfusion injury in rat liver. Am J P GI. 1991; 260(3): G355-G362.

14. Gonzalez-Martin G, Dominguez AR, Guevara A. Pharmacokinetics and hepatotoxicity of diclofenac using an isolated perfused rat liver. Biomed Pharmacother. 1997; 51(4): 170-175.

15. Wolkoff AW, Johansen KL, Goeser T. The isolated perfused rat liver: preparation and application. Anal Biochem. 1987; 167(1): 1-14.

16. Krebs HA, Henseleit K. Untersuchungenüber die HarnstoffbildungimTierkörper, Hoppe-Seyler's Z. Physiol Chem. 1932; 210: $33-66$

17. Bessem M, Hart NA, Tolba R, et al. The isolated perfused rat liver: Standardization of a time-honoured model. Lab Anim. 2006; 40(3): 236-246.

18. Sherill BC, Dietschy JM. Characterization of the sinusoidal transport process responsible for the uptake of chylomicrones by the liver. J Biol Chem. 1978; 253(6): 1859-1867.

19. Belzer FO, Southard JH. Principales of solid-organ preservation by cold storage. Transplant. 1988; 45(4): 673:676.

20. Mochida S, Arai M, Ohno A, et al. Oxidative stress in hepatocytes and stimulatory state of Kupffer cells after reperfusion differ between warm and cold ischemia in rats. Liver. 1994; 14: 234-240.

21. Kakkar V, Muppu SK, Chopra K, et al. Curcumin loaded solid lipid nanoparticles: An efficient formulation approach for cerebral ischemic reperfusion injury in rats. Eur J Pharm Biopharm. 2013; 85: 339-45.

22. Harada H, Hines IN, Flores S, et al. Role of NADPH oxidasederived superoxide in reduced size liver ischemia and reperfusion injury. Arch Biochem Biophys. 2004; 423: 103-108.

23. He SQ Zhang YH, Venugopal SK, et al. Delivery of antioxidative enzyme genes protects against ischemia/reperfusioninduced liver injury in mice. Liver Transpl. 2006; 12: 1869-79.

24. Kim YM, de Vera ME, Watkins SC, et al. Nitric oxide protect cultured rat hepatocytes from tumor necrosis factor-alpha-induced apoptosis by inducing heat shock protein 70 expression. J Biol Chem. 1997; 272 1402.

25. Zaouali M, Ben Abdennebi H, Padrissa AS, et al. Pharmacological strategies against cold ischemia reperfusion injury. Expert Opin Pharmacother. 2010; 11: 535.

26. Rahman MF, Siddiqui MKJ,Jamil K. Acid and alkaline phosphatase activities in a novel phosphorothionate (RPR-11) treated male and female rats. Evidence of dose and time-dependent response. Drug Chem Toxicol. 2000; 23(3): 497-509.

27. He SQ Zhang YH, Venugopal SK, et al. Delivery of antioxidative enzyme genes protects against ischemia/reperfusion-induced liver injury in mice. Liver Transpl. 2006; 12(12): 1869-1879.

28. Mannervik B, Danielson UH. Glutathione transferases-structure and catalytic activit. Crit Rev Biochem. 1988; 23(3): 283-337.

29. Jaeschke H. Molecular mechanisms of hepatic ischemia-reperfusion injury and preconditioning. Am J Physiol Gastrointest Liver Physiol. 2003; 284: G15-G26.

30. Lentsh $\mathrm{AB}$, Kato $\mathrm{A}$, Yoshidome $\mathrm{H}$, et al. Inflammatory mechanism and therapeutic strategies for warm hepatic ischemia reperfusion injury. Hepatol. 2000; 32(2): 169:173.

31. Jaeschke H. Mechanisms of liver injury. II. Mechanisms of neutrophilinduced liver cell injury during hepatic ischemia-reperfusion and other acute inflammatory conditions. Am J Physiol Gastrointest Liver Physiol. 2006; 290(6): G1083-G1088.

32. Dezfulian C, Raat N, Sruti Sa, et al. Role of the anion nitrite in ischemiareperfusion cytoprotection and therapeutics. Cardiovascular Research. 2007; 75: 327-338.

33. Kume M, Banafsche R, Yamamoto $Y$, et al. Dynamic changes of postischemic hepatic microcirculation improved by a pre-treatment of phosphodiesterase-3 inhibitor, milrinone. J Surg Res. 2006; 136: 209.

34. Chattopadhay P, Verma N, Verma A, et al. L-Arginine protects from pringle manoeuvere of ischemia-repefusion-induced liver injury. Biol Pharm Bull. 2008; 31: 890.

35. Quintana AB, Rodriguez JV, Scandizzi AL, et al. The benefit of adding sodium nitroprusside (NPNa) or S-nitroso-gluthation (GNSO) to the University of Wisconsin solution (UW) to prevent morophological alterations during cold preservation/reperfusion of rat livers. Ann Hepatol. 2003; 2: 87.

36. Rodriguez JV, Guibert EE, Quintana A, et al. Role of sodium nitroprusside in the improvement of rat liver preservation in University of Wisconsin solution: A study in the isolated perfused liver model. J Surg Res. 1999; 87: 201.

37. Kuroki I, Miyazaki T, Mizukami I, et al. Effect of sodium nitroprusside on ischemia-reperfusion injuries of rat liver. Hepato-Gastroenterology. 2004; 51: 1404-1407.

38. Godber B, Doel J, Sapkota G, et al. Reduction of nitrite to nitric oxide catalyzed by xanthine oxidoreductase. J Biol Chem. 2000; 275: 7757.

39. Nagababu E, Ramasamy S, Abrenethy D, et al. Active nitric oxide produced in the red cell under hypoxic conditions by deoxyhemoglobinmediated nitrite reduction.J Biol Chem. 2003; 278: 46349.

40. Zweier J, Wang P, Samouilov A, et al. Enzyme-independent formation of nitric oxide in biological tissues. Nat Med.1995; 1: 804.

41. Duranski MR, Greer JJ, Dejam A, et al. Cytoprotective effects of nitrite during in vivo ischemia-reperfusion of the heart and liver. J Clin Invest. 2005; 115: 1232

42. Szabó C. Multiple pathway of peroxynitrite cytotoxicity. Toxico let 2003; 140: 105-112.

43. Cherif-Sayadi A, Hadj ATK, Bejoui M, et al. Effects of nitrite addition to IGL-1 solution on rat liver preservation. Ann Transplant. 2016; 21: 602-610.

44. Bockow BI. United States Patent No. 05709855. 1998.

45. Romay CH, González R, Ledón N , et al. C-Phycocyanin: a biliprotein with antioxydant, anti-Inflammatory and neuroprotective effects. Curr Protein Pept Sci. 2003; 4(3): 207-216.

46. Bhat VB, Madyastha KM. Scavenging of peroxynitrite by phycocyanin and phycocyanobilin from Spirulina platensis: Protection against oxidative damage to DNA. Biochem Biophys Res Commun. 2001; 285(2): 262-266.

47. Estrada JP, Bescós PB, Del Fresno AV. Antioxidant activity of different Fractions of Spirulina platensis protean extract. Il farmaco. 2001; 56(5): 497-500.

48. Bhat VB, Madyastha KM. C-Phycocyanin: a Potent Peroxyl Radical Scavenger in Vivo and in Vitro. Biochem Biophys Res Commun. 2000; 275(1): 20-25. 
49. Hirata T, Tanaka M, Ooike M, et al. Antioxidant activities of phycocyanobilin prepared from Spirulinaplatensis. J Appl Phycol 2000; 12(3): 435-439.

50. Stocker R, Glazer AN, Ames BN. Antioxidant activity of albumin-bound bilirubin, Proc Natl Acad Sci. 1987; 84(16): 5918-5922.

51. Stocker R, Yamamoto Y, McDonagh AF, et al. Bilirubin is an antioxidant of possible physiological importance. Sci. 1987; 235: 1043-1046.
52. Stocker R, McDonagh AF, Glazer AN, et al. Antioxidant activities of bile pigments: biliverdin and bilirubin. Methods Enzymol. 1990;1 86: 301-309.

53. Gdara NB, Belgacem A, Khemiri I, et al. Protective effects of phycocyanin on ischemia/reperfusion liver injuries. Biomedicine \& Pharmacotherapy. 2018; 102: 196-202. 